\title{
PRÁTICAS EDUCATIVAS E A PROMOÇÃO DA ALIMENTAÇÃO SAUDÁVEL: EXPERIÊNCIAS NO ENSINO INTEGRADO NO IFPB
}

\author{
Silvia Helena Valente Bastos*; Gilcean Silva Alves \\ *E-mail: sili.bastos@gmail.com \\ Instituto Federal de Educação, Ciência e Tecnologia da Paraíba \\ DOI: $10.15628 /$ rbept.2020.10306
}

Artigo submetido em: jun/2020 e aceito em: ago/2020

\begin{abstract}
RESUMO
Práticas alimentares inadequadas predispõem ao desenvolvimento de diversas doenças. Incentivar a alimentação saudável no ambiente escolar e durante a adolescência auxilia na promoção de saúde. O objetivo deste estudo foi investigar as contribuições da educação alimentar e nutricional (EAN) para promoção da alimentação saudável no ensino médio integrado. Esta pesquisa descritiva e qualitativa, realizou a análise temática de conteúdo de ações de EAN desenvolvidas com discentes de controle ambiental do IFPB. Como resultados percebeu-se a ampliação de conhecimentos sobre alimentação saudável, a intenção ou modificação de práticas alimentares e a compreensão de como escolhas alimentares afetam o corpo humano e o meio ambiente. Foi possível concluir que é relevante abordar esta temática no currículo integrado para promoção de saúde e para processo de ensino e aprendizagem.
\end{abstract}

Palavras-chave: Práticas alimentares. Educação alimentar e nutricional. Ensino médio integrado. Construção de conhecimentos.

\section{EDUCATIONAL PRACTICES AND PROMOTION OF HEALTHY EATING: EXPERIENCES IN INTEGRATED EDUCATION AT IFPB}

\begin{abstract}
Inadequate dietary practices predispose to the development of several diseases. Encouraging healthy eating in the school environment and during adolescence helps to promote health. The aim of this study was to investigate the contributions of food and nutrition education (FNE) to promote healthy food in integrated high school. This descriptive and qualitative research carried out the thematic content analysis of FNE actions developed with IFPB environmental control students. As a result, there was an increase in knowledge about healthy eating, the intention or modification of eating practices and an understanding of how food choices affect the human body and the environment. It was concluded that it is relevant to address this issue in the integrated curriculum for health promotion and for the teaching and learning process.
\end{abstract}

Keywords: Eating practices. Food and nutrition education. Integrated high school. Knowledge building. 


\section{INTRODUÇÃO}

É de comum acordo na literatura que doenças crônicas não transmissíveis (DCNTs) são responsáveis por mais da metade do índice de mortalidade na população mundial, tornando-as um dos principais problemas de saúde pública atuais (WHO, 2014).

A pesquisa de Vigilância de Fatores de Risco e Proteção para Doenças Crônicas por Inquérito Telefônico (VIGITEL) indicou que mais da metade dos brasileiros, em média, $55,7 \%$, estão com excesso de peso e mostrou um aumento de $67,8 \%$ no número de brasileiros obesos entre 2006 e 2018, fazendo com que a prevalência dessa doença aumentasse de $11,8 \% \mathrm{em}$ 2006 para 19,8\% em 2018 (BRASIL, 2019).

Estilo de vida inadequados caracterizados pelo tabagismo, inatividade física, consumo excessivo de bebidas alcoólicas e práticas alimentares não saudáveis são os principais fatores de riscos para o desenvolvimento de doenças crônicas não transmissíveis (WHO, 2014).

Neste contexto, tem-se a adolescência, período de transição entre a infância e a vida adulta, que abrange pessoas de 10 a 19 anos de idade. Momento de vulnerabilidade nutricional em virtude do aumento das necessidades nutricionais, do padrão alimentar e estilo de vida adotados e da forte predisposição a influências externas sobre os aspectos comportamentais (BRASIL, 2017).

Nesta fase, os hábitos alimentares e a condição de saúde estabelecidos tendem a permanecer durante a vida adulta, por isso é o momento ideal para implementar a alimentação saudável (BRASIL, 2017).

De acordo com Carneiro et al. (2017), o sedentarismo, o aumento do consumo de alimentos processados e ultraprocessados e a redução da ingestão de frutas, legumes e verduras são os principais determinantes da obesidade e sobrepeso na adolescência.

Corroborando com este pensamento, o Ministério da Saúde (2014) indica que as práticas alimentares adotadas pela sociedade contemporânea, tais como diminuição do consumo de alimentos in natura e minimamente processados, a crescente aquisição de alimentos processados e ultraprocessados, falta de otimização do tempo para o preparo de refeições, a cultura de comer fora de casa priorizando as redes de fast food e a influência da mídia contribuem no desenvolvimento de DCNTs.

Neste cenário, torna-se imprescindível visualizar o ambiente escolar como um espaço potencial para realização de ações que promovam saúde a partir de uma concepção ampla de alimentação saudável. Em sua essência, a alimentação saudável vai além do consumo de alimentos de forma equilibrada, harmônica, variada e que atendam às necessidades nutricionais 
dos indivíduos. Compreende o ser humano como ser integral, perpassando também pelos aspectos econômicos, culturais, emocionais, sociais e que seja atrelada à realidade onde estes estão inseridos (BRASIL, 2012).

Pensar a alimentação saudável de forma ampla é possível por meio da educação alimentar e nutricional (EAN), que, para Boog (2013) tem o papel de respeitar os conhecimentos prévios e auxiliar em decisões alimentares mais saudáveis e sustentáveis. Implementar a EAN na escola é oportuno e eficaz por ser espaço de interação e reflexão, com funções educativas e formadoras, capaz de contribuir para o desenvolvimento psicológico e emocional dos alunos e possibilitar o compartilhamento de hábitos, preferências e modismo (SILVEIRA et al., 2011).

A EAN, no âmbito escolar, possibilita a aprendizagem dos princípios gerais da alimentação e nutrição, orienta comportamentos específicos e auxilia escolhas mais conscientes ao longo da vida, estimulando a adoção de bons hábitos alimentares, minimizando a insegurança alimentar e nutricional e auxiliando na garantia do bem-estar e a qualidade de vida dos estudantes (MAGALHÃES; CAVALCANTE, 2019).

Para que esta possa trazer contribuições significativas deve ser realizada de forma contínua e permanente, transdisciplinar, intersetorial e multiprofissional a partir da utilização de recursos educacionais problematizadores e ativos que possibilitem a construção de conhecimentos de forma interativa e dialógica (BRASIL, 2012).

Promover alimentação saudável considerando os aspectos supracitados amplia os conhecimentos relacionados às práticas alimentares, fomenta a autonomia nas escolhas e permite a reeducação alimentar com modificação concreta dos hábitos alimentares atuando na promoção, melhoria ou recuperação da saúde.

Neste sentido, este artigo resulta de uma pesquisa de mestrado profissional em educação que teve como objetivo investigar as contribuições da educação alimentar e nutricional através do ensino da fisiologia humana para promoção da alimentação saudável no ensino técnico integrado ao médio do curso técnico em Controle Ambiental, no IFPB, Campus João Pessoa.

\section{METODOLOGIA}

A presente pesquisa do tipo descritiva e com abordagem qualitativa foi realizada, em 2019, com a turma do $3^{\circ}$ ano do ensino técnico integrado de Controle Ambiental, Campus João Pessoa, do Instituto Federal de Educação, Ciência e Tecnologia da Paraíba (IFPB), localizado na cidade de João Pessoa, capital da Paraíba, a escolha pelo curso de Controle Ambiental se 
deu por possibilitar que as ações de educação alimentar e nutricional fossem desenvolvidas considerando a formação profissional.

Foram incluídos na pesquisa os discentes que cursaram o $3^{\circ}$ ano de controle ambiental no ano de 2019 , na faixa etária de adolescentes, que apresentaram o termo de consentimento de seus pais ou responsáveis e o termo de assentimento devidamente assinados para participarem da pesquisa. Foram excluídos os estudantes que não compareceram a $80 \%$ dos encontros. Desta forma, participaram deste estudo 22 estudantes.

As ações ocorreram em 5 (cinco) encontros de aproximadamente 2 (duas) horas cada que, durante as aulas de biologia e educação física buscando relacionar o ensino da fisiologia humana e a prática de atividade física à alimentação saudável e adequada por meio de metodologias ativas, participativas e construtivistas atrelando a teoria à prática, considerando 0 contexto onde os estudantes estão inseridos.

Os encontros foram intitulados por Classificação dos alimentos e uso racional de sal, açúcar e gorduras; Os grupos dos alimentos e a ressignificação do ato de comer; Reconhecer e superar os obstáculos para uma alimentação saudável e adequada; Habilidades culinárias e o aproveitamento integral dos alimentos; e Olhar crítico da publicidade e difusão de informações de alimentação e nutrição

O conteúdo abordado baseou-se na visão ampla que envolve a alimentação saudável e adequada presente no Guia Alimentar para a População Brasileira (2014), elaborado pelo Ministério da Saúde e teve inspiração no Instrutivo: Metodologia de trabalho em grupos para ações de alimentação e nutrição na atenção básica desenvolvido pelo Ministério da Saúde em parceira com a Universidade Federal de Minas Gerais (2016).

A avaliação ocorreu durante e após a realização das ações de educação alimentar e nutricional, através de estratégias somativa, que traz uma avaliação global de todo o processo, e formativa, que visa auxiliar o educador a compreender como está o processo de aprendizagem e identificar o que pode ser melhorado (CARVALHO, et al., 2016).

$\mathrm{Na}$ avaliação, buscou-se identificar a ampliação dos conhecimentos sobre alimentação saudável, a capacidade de relacionar as práticas alimentares com o ensino da fisiologia humana e o desenvolvimento do olhar crítico de como as escolhas alimentares afetam o contexto ambiental.

Com relação aos dados, optou-se pela análise de conteúdo, na modalidade temática, proposta por Minayo (2006), para preservar a identidade dos estudantes, que foi substituída pelo uso de codificação ( $E 1$, E2...). Este estudo foi aprovado pelo Comitê de Ética em Pesquisa (CEP), do Instituto Federal da Paraíba (IFPB) pelo parecer de $\mathrm{n}^{\circ} 3.314 .790$ do ano de 2019. 


\section{RESULTADOS E DISCUSSÕES}

\subsection{CLASSIFICAÇÃO DOS ALIMENTOS E USO RACIONAL DE SAL, AÇÚCAR E GORDURAS}

No primeiro encontro, para estreitar os laços e permitir que todos se conhecessem melhor utilizou-se a dinâmica de apresentação intitulada "Boneco vazio". Nela os participantes receberam um papel A4 com a imagem de um boneco vazio em que deveriam colocar seu nome, uma qualidade, um defeito, o que gosta de fazer, seu alimento preferido, um alimento que lembra sua infância e, se houvesse, uma dúvida sobre alimentação e nutrição para ser discutida como questão problema nos próximos encontros, após o preenchimento todos se apresentaram.

Em seguida para construir um espaço de compartilhamento de experiências e troca de conhecimentos perguntou-se: "Como está sua alimentação?" e "Para você o que é uma alimentação saudável?".

Posteriormente assistiu-se ao vídeo "Os dez passos para a alimentação saudável e adequada", elaborado pela Organização PanAmericana de Saúde (OPAS) e destacou-se que aquele encontro iria enfatizar os 4 primeiros passos para uma alimentação adequada e saudável recomendada pelo Guia Alimentar para a População Brasileira (BRASIL, 2014).

Para isto, explicou-se a classificação dos alimentos quanto ao grau de processamento e foi desenvolvida a dinâmica "Vamos à feira". Divididos em grupos e com auxílio de um encarte fictício de supermercado, os estudantes puderam comprar alimentos considerando a pergunta "O que você compraria com 60,00 reais?". Para concluir, representantes dos grupos apresentaram suas compras e quanto gastaram, permitindo a avaliação quanto a tipos de alimentos comprados e do uso racional dos recursos financeiros, conforme indica a Figura 1.

Figura 1: Resultado da dinâmica grupo 1
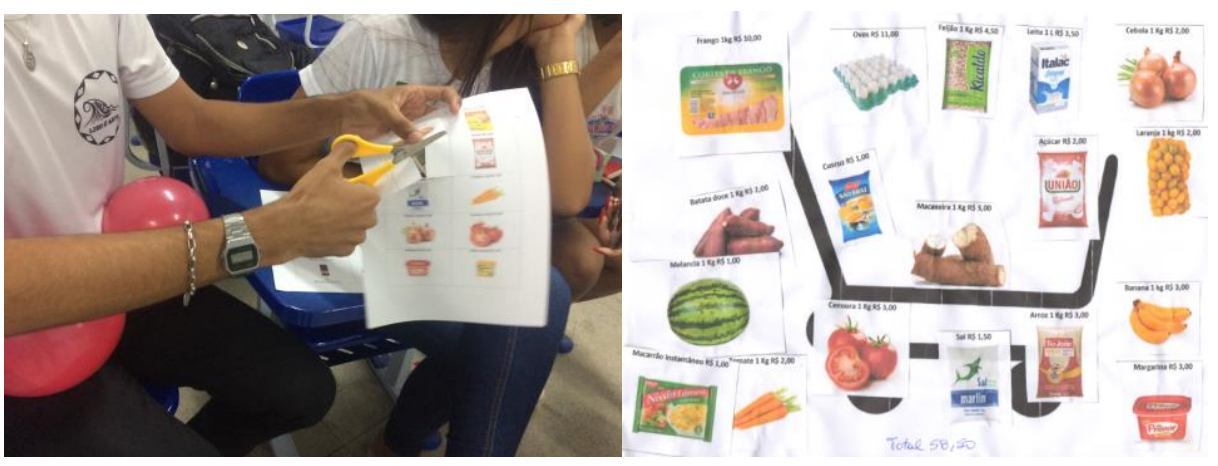
Fonte: desenvolvido pelos autores (2019).

Para melhor entendimento sobre cada tipo de alimentos, citaram-se alguns exemplos de como alimentos in natura ou minimamente processados se tornam processados ou ultraprocessados, incentivando o consumo de alimentos in natura e minimamente processados. Logo após, fez-se a dinâmica "Entendendo o rótulo dos alimentos" para mostrar a diferença da qualidade nutricional dos alimentos conforme seu grau de processamento a partir da comparação da tabela nutricional e da lista de ingredientes contidos nos alimentos.

A dinâmica oportunizou apontar os excessos de gordura, sal e açúcar e a presença de conservantes, estabilizantes, corantes entre outros aditivos presentes em maior quantidade nos alimentos ultraprocessados.

Após compreender os possíveis malefícios que os excessos de alimentos processados e ultraprocessados podem trazer para a saúde das pessoas, discutiram-se os seus efeitos danosos para o meio ambiente com a pergunta "A minha alimentação pode afetar o meio ambiente?" e do vídeo "Você come e muda o planeta", elaborado por World Wildlife Fund (WWFBrasil).

Para finalizar, fez-se a dinâmica avaliativa "Cola aqui, o que foi pra mim", entregou-se dois post-it aos participantes para responderem às perguntas "O que foi novo para mim nesse encontro?" e "Que pequena ação posso fazer para melhorar minha alimentação?", na medida em que respondiam colavam na cartolina fixada no quadro correspondente a cada pergunta, conforme mostra a Figura 2.

Figura 2: Dinâmica - Cola aqui, o que foi pra mim

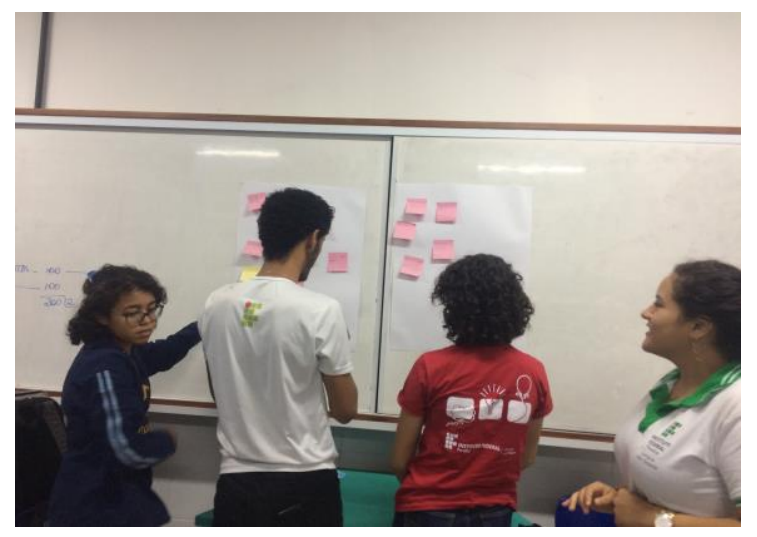

Fonte: desenvolvido pelos autores (2019) 


\subsection{OS GRUPOS DOS ALIMENTOS E A RESSIGNIFICAÇÃO DO ATO DE COMER}

Este encontro iniciou com o relato dos estudantes sobre a execução da pequena ação para melhorar a alimentação que se propuseram no final do encontro anterior. Depois fez-se a dinâmica "Alimentos de onde vêm e onde podem chegar", em que cada estudante recebeu um cartão, de forma aleatória, contendo um alimento dos diferentes tipos, podendo ser in natura, minimamente processado, processado ou ultraprocessado, os quais deveriam se agrupar de acordo com o alimento que possuíam.

Quando os grupos estavam formados deveriam encontrar os alimentos complementares ao que tinham recebido, por exemplo, o que recebeu 0 abacaxi encontrar como ele se torna minimamente processado, processado e ultraprocessado. Para finalizar um representante de cada grupo apresentou os alimentos encontrados e relembraram-se os quatro primeiros passos para uma alimentação saudável e adequada.

A questão problema "Como posso combinar nutricionalmente os alimentos para me alimentar melhor?" permitiu a troca de conhecimentos sobre os grupos de alimentos descritos no Guia Alimentar, possibilitando conhecer mais sobre os alimentos que os constituem, nutrientes que fornecem, as contribuições para saúde e para prática de atividade física e como combiná-los para uma alimentação saudável e adequada.

Considerando o conhecimento construído desenvolveu-se a dinâmica "O prato do dia", em que cada grupo recebeu a imagem de um prato vazio e ficou responsável por elaborar a combinação de alimentos para compor uma refeição. Assim um grupo ficou responsável pelo café da manhã, outro pelo almoço, seguindo a mesma regra para o lanche e o jantar. Para concluir, representantes dos grupos apresentaram as suas sugestões e abriu-se 0 espaço para discussões com sugestões dos outros grupos e as contribuições e provocações da facilitadora, com relação à quantidade e qualidade dos alimentos escolhidos para uma refeição saudável e adequada, vide Figura 3. 
Figura 3: Resultado dinâmica grupo 3

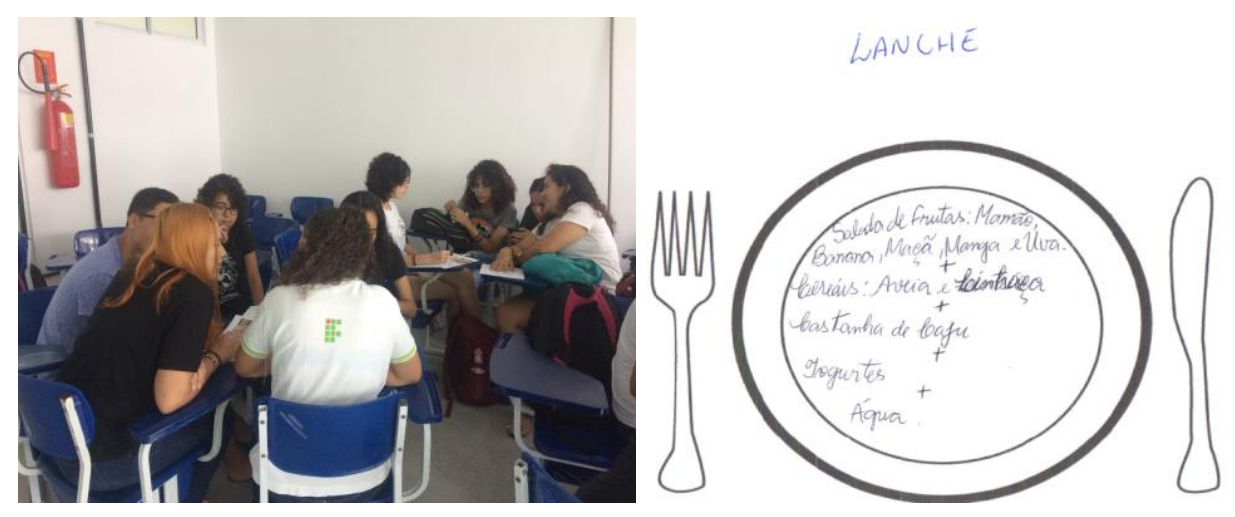

Fonte: desenvolvido pelos autores (2019)

Em seguida, para introduzir a discussão: como ressignificar o ato de comer, utilizou-se a questão problema "Como diferenciar a fome da vontade de comer?", procedeu-se a uma breve discussão e assistiu-se ao vídeo da Nutricionista Lara Natacci, para o canal BemStar com Márcio Atalla, intitulado "Fome emocional x Fome fisiológica". Criando-se ambiente propício para construção de conhecimentos sobre o quinto passo para alimentação saudável, a partir de uma roda de conversas impulsionada pelas seguintes inquietações: Como estou comendo? Tenho atenção ao que consumo? Como sozinho ou acompanhado? Como por fome ou vontade de comer? Como devagar, em ambientes tranquilos, confortáveis e limpos?

Para finalizar este encontro, utilizou a dinâmica avaliativa "Que bom, que pena e que tal" em que cada participante recebeu uma folha tamanho ofício com estas expressões e deveriam descrever, para cada expressão, o que o encontro e os conhecimentos construídos representaram.

\subsection{RECONHECER E SUPERAR OS OBSTÁCULOS PARA UMA ALIMENTAÇÃO SAUDÁVEL E ADEQUADA}

$O$ terceiro encontro iniciou com a dinâmica "O que meus sentidos conseguem perceber" objetivando estimular a percepção dos alimentos através dos sentidos. A facilitadora convidou 5 alunos voluntários para adivinharem os alimentos utilizando apenas um dos sentidos. $O$ estímulo ao tato deu-se com uma tangerina, para o paladar optou-se pela uva, o olfato foi sentido pela hortelã, a audição foi provocada pelo áudio de pipoca estourando e a visão foi percebida pelo gengibre.

Para esta dinâmica, utilizou-se uma venda de olhos e teve-se todos os cuidados para que apenas um sentido estivesse acessível. Ao final, os participantes compartilharam as dificuldades encontradas para identificar os alimentos e provocou-se a reflexão de como os sentidos interferem nas 
escolhas alimentares e como a indústria alimentícia cria mecanismos de tornar os alimentos mais atraentes aos sentidos independentemente das quantidades de sal, açúcar e gorduras.

Em seguida, perguntou-se "Quais as principais dificuldades que você possui para se alimentar melhor?", a fim de provocar uma reflexão da realidade que vivenciam e das dificuldades para a alimentação saudável e adequada, buscando a construção coletiva de estratégias para superá-las. Este momento permitiu conhecer os obstáculos custo, oferta, informação, habilidades culinárias, tempo e publicidade e aprofundou os conhecimentos sobre os sexto e nono passos para uma alimentação saudável e adequada.

Para tentar superar os obstáculos custo e oferta, realizou-se a dinâmica "Vamos plantar" a fim de estimular a construção de hortas domésticas sustentáveis a partir da plantação de temperos. Antes de iniciar a dinâmica assistiu-se o vídeo "Horta urbana", produzido pelo Minuto ITV urbanismo.

Para esta dinâmica, os alunos foram divididos em 5 grupos, cada grupo recebeu uma garrafa pet, tesoura e um envelope contendo sementes de temperos tais como (coentro, salsa, cebolinha, manjericão, pimenta). Disponibilizou-se aos grupos, argila expandida, terra para plantio e água e ensinou-se o passo a passo possibilitando que cada grupo plantasse seu tempero. A dinâmica propiciou ainda a reflexão "Como tornar nossa horta mais sustentável?" e apresentaram-se algumas imagens e alternativas para construção de hortas sustentáveis com os benefícios que estas possuem, conforme aponta a Figura 4.

Figura 4: Dinâmica vamos plantar

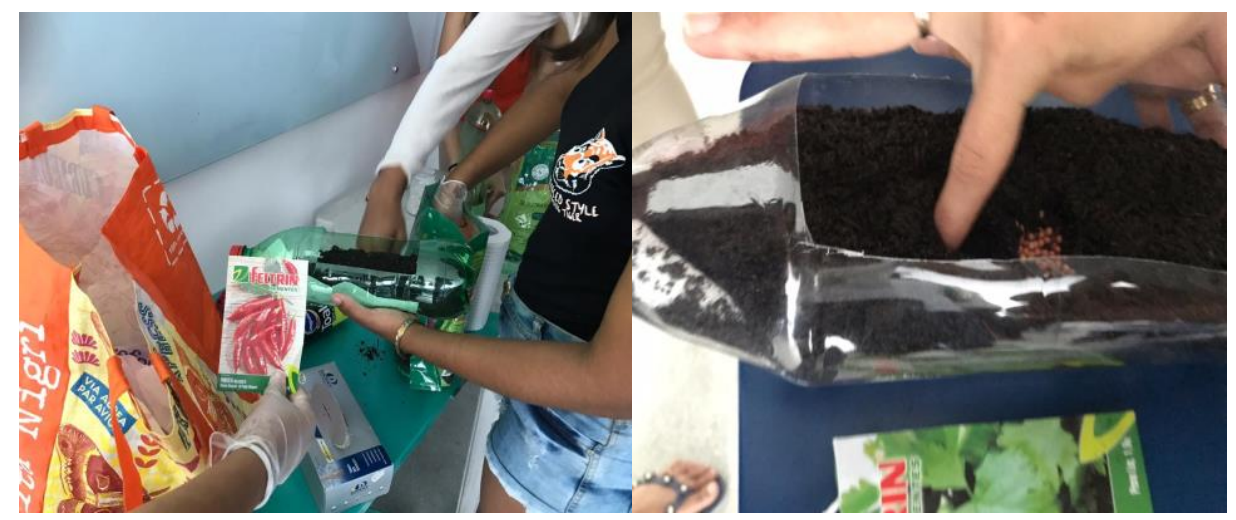

Fonte: desenvolvido pelos autores (2019)

A partir da pergunta "Como controlar a alimentação quando se passa muito tempo fora de casa e tem mais opções de lanches não saudáveis?" fezse uma breve revisão de todos os conhecimentos construídos. Para concluir, 
avaliou-se o encontro com o jogo virtual no site https://kahoot.it/ e sugeriu-se que compartilhassem entre si, no grupo da turma de WhatsApp, as principais dificuldades encontradas durante a semana para se alimentarem de forma mais saudável e sustentável.

\subsection{HABILIDADES CULINÁRIAS E O APROVEITAMENTO INTEGRAL DOS ALIMENTOS}

Este encontro retomou a pergunta "Como controlar a alimentação quando se passa muito tempo fora de casa e tem mais opções de lanches não saudáveis?" para aprofundar os sétimo e oitavo passos para uma alimentação saudável e adequada.

Para otimizar o tempo e desenvolver habilidades culinárias, realizou-se a dinâmica "Oficina culinária". Antes de iniciar a oficina discutiu-se sobre o aproveitamento integral dos alimentos, enfatizando seus benéficos nutricionais, as contribuições dessa prática para o meio ambiente e a economia financeira que a utilização o alimento integralmente proporciona, conforme mostra a Figura 5.

Figura 5: Oficina culinária

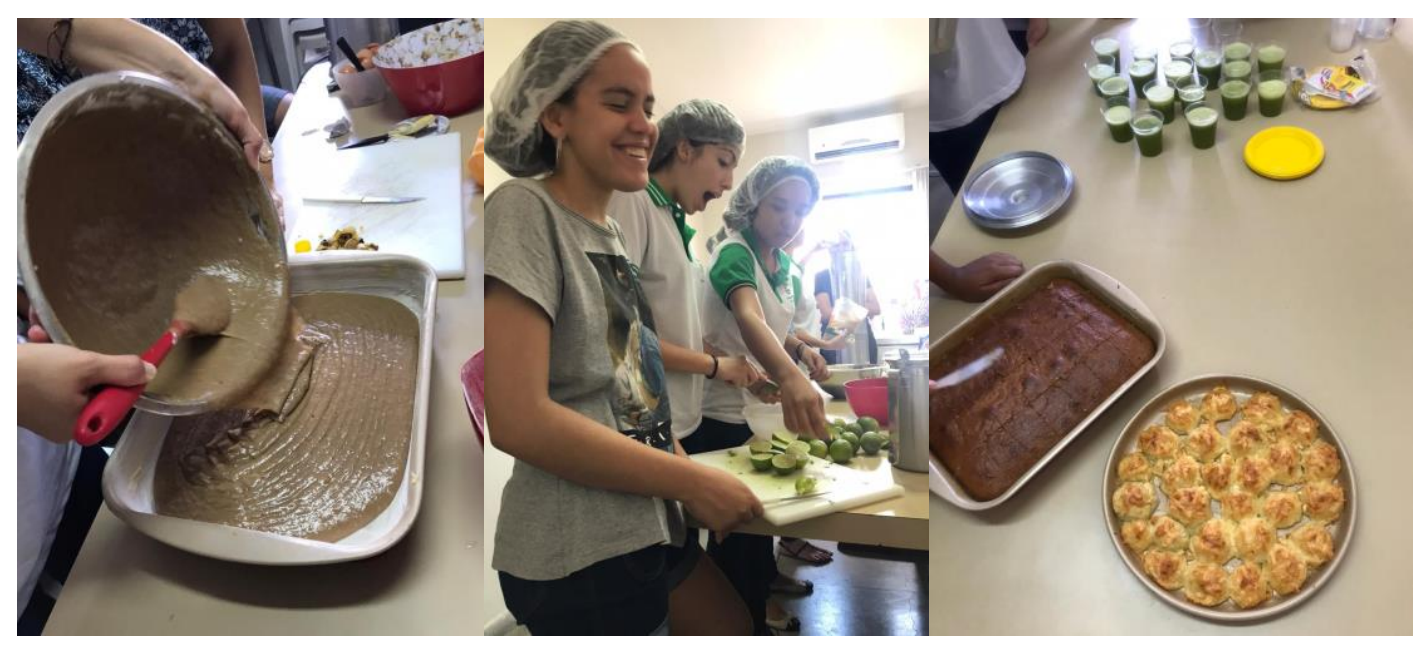

Fonte: desenvolvido pelos autores (2019)

O objetivo da oficina foi a construção coletiva de um lanche saudável, no espaço de copa e refeitório do IFPB. Antes de iniciar a prática, solicitou-se que os participantes lavassem bem as mãos, colocassem touca, evitassem conversar durante o preparo dos alimentos e que guardassem seus pertences pessoais em um espaço destinado para isso. 
Quando todos estavam preparados, entregou-se um livrinho de receitas e a facilitadora informou que iriam preparar o suco da horta, bolo da casca de banana e o mandioqueijo. À medida que se ia lendo o passo a passo do preparo, os estudantes revezavam-se na execução dos procedimentos de preparo, de modo que todos colaborassem do preparo e lavagem dos utensílios utilizados tornando $o$ ato de preparar os alimentos fácil, rápido, divertido, além de supersaboroso.

Quando os alimentos estavam preparados, convidaram-se todos a degustarem e a saborearem o lanche nutritivo que prepararam coletivamente. Por fim, desafiaram-se os alunos a escolherem uma das receitas do livrinho e, em grupo, fazê-la, para que no último encontro todos pudessem degustála.

\subsection{OLHAR CRÍTICO DA PUBLICIDADE E DIFUSÃO DE INFORMAÇÕES DE ALIMENTAÇÃO E NUTRIÇÃO}

O último encontro começou com a discussão de como as informações são disponibilizadas e a real intenção da publicidade em vender produtos processados e ultraprocessados. Para enfatizar esta discussão, fez-se a dinâmica "Fato ou fake" com o intuito de provocar nos alunos o senso crítico sobre informações disponíveis nas mídias e redes sociais. Para isso, cada participante recebeu uma plaquinha com a palavra fato de um lado e fake do outro, na medida em que afirmativas eram lançadas os participantes sinalizavam o que aquela expressão representava.

Ao final este momento, assistiu-se à reportagem do jornal Fala Brasil apresentado pela Rede Record de Televisão, intitulada por "Anvisa vai fazer consulta pública sobre o novo modelo de rótulos de alimentos", para apresentar a proposta de reformulação dos rótulos dos alimentos embalados acrescentando alerta na frente da embalagem de alimentos com altas quantidades de açúcar, sal e gorduras, sugerida pela Agencia Nacional de Vigilância Sanitária (ANVISA).

Para abordar o décimo passo para uma alimentação saudável e adequada, realizou-se a dinâmica "Vejo, veja, o que você vê?". Nesta dinâmica assistiu-se a duas propagandas de alimentos ultraprocessados e, ao final de cada vídeo, provocou-se uma discussão sobre sua real intenção.

A partir da propaganda do McDonald's: \#FomeDeMC, a discussão atentou para a pressão psicológica que esta provoca, incentivando a fome psicológica com o slogan "Fome de Mc, só passa quando você passa no Mc". $\mathrm{E}$ a propaganda do refrigerante Coca Cola: Coca Cola vai deixar todo mundo com sede, trouxe as diversas sensações que ela tenta passar, como ela 
estimula a imaginação e provocar todos os seus sentidos do sistema sensorial fazendo com que você sinta vontade de consumir Coca Cola.

Depois de analisar as propagandas criticamente foi o momento da dinâmica "Luz, câmera e ação", em que a turma foi dividida em 4 grupos e entregou-se a cada grupo um alimento in natura ou minimamente processado tais como maçã, abacaxi, massa de cuscuz e laranja e os estudantes prepararam uma propaganda dos alimentos e apresentaram aos colegas. Para finalizar o ciclo de encontros realizou-se uma avaliação global das construções realizadas durante todos os encontros e fez-se a degustação dos pratos que os estudantes levaram, vide imagem 6.

Figura 6: Dinâmica luz câmera e ação

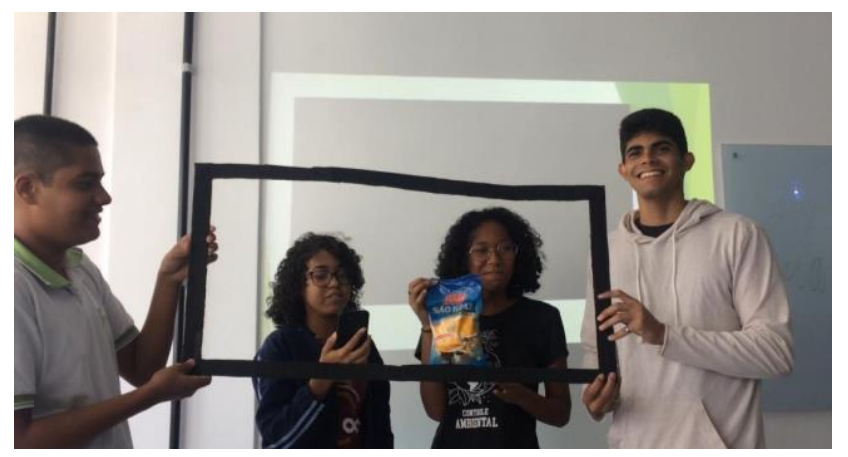

Fonte: Autores (2019)

\subsection{AVALIAÇÃO}

A avaliação para identificar se as ações cumpriram seu objetivo deu-se com estratégias somativas e formativas e para a análise foram criadas 4 categorias, a partir do agrupamento das respostas, ampliação de conhecimentos sobre alimentação saudável, a interferência das práticas alimentares na saúde, a modificação de hábitos alimentares e a influência das práticas alimentares para o meio ambiente, que serão exploradas a seguir.

\subsubsection{Ampliação de conhecimentos sobre alimentação saudável}

O processo de construção coletiva de conhecimentos provocou mudanças significativas na compreensão dos diversos aspectos que envolvem alimentação saudável, visto que, para além do biológico, esta perpassa por questões culturais, emocionais, afetivas, sociais, políticas e econômicas e tal entendimento pode ser percebido nas falas: 
Aprendi que cada garfada tem um significado político, econômico e social, coma de forma sustentável. (E21).

Tal percepção possibilitou identificar que as ações de educação alimentar e nutricional realizadas com os discentes conseguiram superar 0 aspecto biológico e técnico voltado à mera ingestão de calorias e nutrientes. Abranger os diversos eixos que envolvem a alimentação saudável permitiu o desenvolvimento de um olhar crítico e a compreensão dos repletos sentidos que circunda o ato de comer.

A ampliação e a construção de conhecimentos construídos sobre alimentação saudável foram perceptível nas seguintes falas:

[...] agora tenho um conhecimento melhor sobre alimentação saudável $[\ldots](\mathrm{E} 1)$.

Nos trouxe muitas informações relevantes sobre os alimentos e hábitos alimentares...aprendemos como nos alimentar melhor, combinando os grupos de alimentos. (E2).

Aprendi sobre como ter uma alimentação mais saudável. (E6).

Nos relatos supracitadas, observou-se o aumento do conhecimento sobre como alimentar-se melhor. Resultados semelhantes foram encontrados no estudo realizado por Costa et al. (2016) ao identificar que a educação alimentar e nutricional permitiu a ampliação dos conhecimentos dos escolares a partir dos depoimentos dos participantes.

As ações ainda permitiram despertar a autonomia na escolha consciente de alimentos, a partir do conhecimento de como se ter uma alimentação saudável, como indicam os discursos:

Passei a ter mais conhecimento de como balancear minha alimentação, como escolher o que vou comer [...] (E5).

Aprendi as melhores combinações de alimentos e como me alimentar melhor. (E8).

Consegui compreender com mais facilidade a importância e o que fazer para obter hábitos alimentares saudáveis. (E10). 
O primeiro passo para fomentar a autonomia nas escolhas alimentares mais assertivas é disponibilizar a informação. Permitir isso a partir da construção coletiva de conhecimentos, considerando o contexto social, econômico e cultural em que os discentes estão inseridos pode impulsionar a intenção de modificar as práticas alimentares, tornando o processo de reeducação alimentar simples, acessível e duradouro.

A classificação dos alimentos e compreensão da importância de limitar o consumo de alimentos processados e evitar os ultraprocessados, foi percebida a partir do entendimento de como estes alimentos podem ser prejudiciais à saúde, como demonstra a fala:

[...] foi bastante produtivo e necessário obter essas informações [...] principalmente em questão dos alimentos ultraprocessados não tinha noção de quão prejudiciais podem ser estes alimentos. (E7).

A indústria alimentícia através da mídia e dos rótulos dos alimentos busca estratégias para captar maior quantidade de consumidores. Descrições como "vitaminado", "livre de colesterol", "rico em vitaminas e minerais", "rico em fibras" são frequentemente visíveis nos rótulos de alimentos ultraprocessados. Ao mesmo tempo, informações como quantidade de sódio, açúcares e gorduras são quase que invisíveis para passarem despercebidas limitando a informação ao consumidor do que de fato estão consumindo. Nesse sentido, ações de educação alimentar e nutricional têm o papel de informar e orientar como reconhecer a partir do rótulo de que se compõem os alimentos industrializados e a fala acima (E7) permitiu identificar como as ações realizadas auxiliaram na compreensão do quão os alimentos processados e ultraprocessados podem ser prejudiciais à saúde.

\subsubsection{A interferência das práticas alimentares na saúde}

As ações de educação alimentar e nutricional possibilitaram aos estudantes relacionar os hábitos alimentares com a saúde e a qualidade de vida, conforme indicam as seguintes falas:

Quando eu como melhor, me sinto melhor e mais disposta. (E3).

Dependendo da minha alimentação tenho mais energia, força e etc. (E6). 
Posso comer coisas que eu gosto, mas fazer isso de uma forma fácil e que faz bem para minha vida. (E17).

Me ajudou muito a entender como melhor me alimentar e viver mais saudável [...] se me alimento melhor fico mais disposto e saudável, se não fico sem coragem, sem saúde. (E22).

Para Costa et al. (2016), ações de educação alimentar e nutricional desenvolvidas de forma lúdica, participativa e interativa promovem a construção de conhecimentos que reverberam na promoção de uma vida mais saudável. Nesse sentido, os resultados encontrados indicam a compreensão dos discentes de como a alimentação afeta a saúde e o entendimento de que escolhas alimentares podem contribuir na promoção da saúde e na melhoria da qualidade de vida.

O entendimento de como a alimentação impacta no funcionamento do corpo humano e no desenvolvimento de doenças também foi identificado pelos discentes, como se observa nas falas:

É possível comer de tudo de maneira equilibrada, e ainda ser saudável [....] é necessário ingerir alimentos benéficos, mais frutas, e ter uma alimentação balanceada para um funcionamento adequado. (E2).

Se você só come besteira seu corpo não vai funcionar $100 \%$. (E13).

Uma prática saudável, muda completamente o funcionamento do corpo, ajudando a prevenir várias doenças e má disposição. (E14).

Aprendi a valorizar os alimentos in natura, notando os benefícios do alimento no funcionamento do corpo. (E18).

As falas acima mostram como os discentes relacionam a fisiologia humana e a ingestão de alimentos, a partir da percepção de que uma alimentação saudável contribui para o funcionamento do corpo, previne doenças e traz benefícios ao organismo. Este resultado demonstra que a educação alimentar e nutricional pode auxiliar na prevenção de doenças crônicas não transmissíveis. Observou-se ainda que a inclusão deste tema transversal no ensino da fisiologia pode promover saúde ao mesmo tempo em que garante maior interação e dinamicidade ao estudo do corpo humano. 


\subsubsection{A modificação de hábitos alimentares}

As ações provocaram e/ou incentivaram mudanças nos hábitos alimentares dos discentes, visto que, de maneira geral, todos afirmaram que modificaram ou pretendem modificar suas práticas alimentares após a participação nas ações de educação alimentar e nutricional, como indicam as falas:

Acho que o primeiro passo é a busca por mudanças...então vou procurar comer coisas mais saudáveis. (E17).

Me ajudou a reeducar minha alimentação. (E9).

[...] me ajudou muito em vários aspectos, já me alimentava bem agora muito mais [...] vou me alimentar o mais saudável possível. (E4).

No estudo realizado por Vaz, Ribeiro e Rufino (2020), foi perceptível que ações de educação alimentar e nutricional incentivam as mudanças de hábitos alimentares. Neste estudo, $90 \%$ dos participantes mostraram-se aptos a melhorar a alimentação, resultado semelhante ao encontrado por esta pesquisa.

Outra modificação importante foi a diminuição do consumo de alimentos ultraprocessados e processados com o aumento do consumo de alimentos in natura como uma das medidas para se ter uma alimentação mais saudável, conforme demonstrado a seguir:

Aprendi a reeducar minha alimentação [...] modificar o meu consumo de alimentos ultraprocessados. (E19).

Vou tentar prestar atenção nos rótulos e evitar os alimentos ultraprocessados [...] selecionando melhor meus alimentos antes de comprar de acordo com sua origem [...] optando por alimentos in natura. (E7).

Aprendi que temos oportunidades de mudarmos nossa alimentação de uma forma fácil [...] temos algumas formas alternativas, como comer mais frutas, e coisas mais naturais. (E20).

Tais falas apontam que os discentes compreenderam a classificação dos alimentos proposta pelo Guia Alimentar e, para além disso, estão 
buscando melhorar a alimentação a partir da diminuição do consumo de alimentos processados e ultraprocessados e um aumento no consumo de alimentos in natura ou minimamente processados. $O$ estudo realizado por Vaz, Ribeiro e Rufino (2020) apresentou resultados semelhantes ao desta pesquisa, nele observaram-se resultados positivos no que se refere à modificação de hábitos alimentares e ao consumo consciente de alimentos.

Outro aspecto observado foi o aumento da autonomia na hora da escolha do que comer, contribuindo para a formação de indivíduos atentos, críticos e conscientes de suas escolhas. O desenvolvimento dessa autonomia apareceu na categoria ampliação do conhecimento e foi identificada também no ato concreto de modificar os hábitos alimentares, conforme indicam os comentários abaixo:

Escolher e prestar mais atenção no que estou comendo [...] aplico o máximo possível, principalmente em casa onde a alimentação saudável é mais fácil. (E3).

Aprendi a escolher melhor meus alimentos [...] incorporar alguns hábitos alimentares [...] combinar melhor os alimentos. (E8).

[...] a partir desse conhecimento, vou tentar melhorar meus hábitos [...] me ajudou na escolha dos alimentos e na consciência de colocar uma alimentação saudável em prática. (E14).

A educação alimentar e nutricional deve ser um canal para construir conhecimentos e estimular a autonomia na escolha de alimentos mais saudáveis, não se trata de ensinar o que comer ou o que abolir das práticas alimentares, mas sim permitir que cada pessoa munida de conhecimentos consiga refletir sobre suas práticas alimentares e identificar o que pode fazer para melhorá-las.

$\mathrm{Na}$ pesquisa realizada por Ávila et al. (2019), as intervenções de educação alimentar e nutricional realizadas impulsionou a formação de hábitos alimentares saudáveis, despertando a autonomia para que os adolescentes sejam os protagonistas de suas escolhas.

Outra questão importante foi o despertar do interesse em desenvolver as habilidades culinárias como estratégia na busca por alimentar-se de forma mais saudável e sustentável, como destacado nas falas a seguir:

Posso tentar ser sustentável através da tentativa de pôr em prática meus dotes culinários. (E4). 
Tenho planos para a melhoria do meu cardápio e maior disposição para prática de produção de alimentos mais saudáveis. (E5).

Para Costa et al. (2016), a prática culinária não se limita à execução de uma preparação, esta facilita o processo de recordação e construção do conteúdo, permite troca de experiências e o envolvimento dos discentes com a elaboração das preparações, despertando maior interesse no consumo do que foi produzido. Nesse sentido, estimular o desenvolvimento de habilidades culinárias como prática educativa através de oficinas permite a participação ativa dos discentes e a superação da dicotomia teoria e prática, contribuindo ainda na promoção da alimentação saudável.

O papel do discente como multiplicador do processo educativo contribuindo para que outras pessoas, como familiares e amigos, possam melhorar os hábitos alimentares foi identificado a partir das seguintes falas:

[...] e que posso ajudar meus amigos a mudar seus hábitos para melhor. (E6).

[...] depois dessas aulas eu pretendo me reeducar e também integrar junto com a minha família. (E13).

Estes fragmentos enfatizam que as ações contribuíram na difusão de conhecimentos e despertaram nos discentes a responsabilidade de partilhálos com seus amigos e familiares. No estudo realizado por Costa et al. (2016), a intervenção apresentou resultado similar ao relevar o importante papel de formação de multiplicadores pela intenção dos participantes de transmitir o que foi aprendido para seus familiares, assim como na pesquisa realizada por Silva et al. (2020) que identificou a extensão aos familiares de mudanças benéficas nos hábitos alimentares após ação de educação alimentares e nutricional.

\subsubsection{A influência das práticas alimentares para o meio ambiente}

Como a alimentação se relaciona ao meio ambiente, essa foi outra contribuição das ações. Verificar se as práticas alimentares afetam diretamente o meio ambiente e que nossas escolhas podem auxiliar na preservação do meio ambiente foi identificado nas seguintes falas: 
[...] os alimentos estão relacionados com o uso da terra e os recursos naturais, então por isso é muito importante uma alimentação saudável e consciente. (E3).

A alimentação é essencial para a vida e uma dieta equilibrada e menos desperdício ajuda o nosso planeta e nos proporciona uma vida melhor. (E14).

Com uma alimentação mais saudável e sustentável eu posso contribuir para o futuro do planeta. (E6).

Resultados semelhantes foram encontrados por Gomes e Teixeira (2017) que com oficinas de culinária com aproveitamento integral dos alimentos possibilitou aos estudantes atentar para a diminuição dos gastos com alimentos, desperdícios, gestão do lixo e os benefícios nutricionais dos alimentos preparados integralmente.

Já o estudo de Silva et al. (2020) possibilitou a abordagem da educação ambiental e alimentar a partir de roda de conversas e da produção de mudas, estas práticas permitiram aos estudantes a construção de conhecimentos sobre essas temáticas e a incorporação de práticas e ideias de sustentabilidade para a vida, a fim de despertar a responsabilidade no cuidado do meio ambiente e da saúde por meio da difusão da alimentação saudável.

A percepção crítica de como os alimentos processados e ultraprocessados impactam no meio ambiente foi percebido em:

[...] alimentação está diretamente relacionada ao meio ambiente, alimentos industrializados aumentam o consumo de embalagens, podendo aumentar a poluição. (E2).

Posso contribuir para o meio ambiente consumindo menos alimentos embalados. (E19).

A compreensão de que adoção de hábitos alimentares saudáveis, priorizando alimentos in natura e minimamente processados contribui para o meio ambiente foi identificada nas falas, além disso estas podem trazer uma relação ao mundo do trabalho, visto que a educação alimentar e nutricional pode ser um elo para discutir controle ambiental contribuindo para a saúde, meio ambiente e na formação profissional desses discentes.

A partir das avaliações somativa e formativas observou-se o potencial transformador das ações de educação alimentar e nutricional. Estas foram capazes de ampliar conhecimentos, modificar ou despertar a intenção de 
modificar as práticas alimentares, evidenciar como as práticas alimentares afetam nossa saúde, estimular o cuidado com o meio ambiente a partir das escolhas alimentares, bem como contribuir para o fomento da autonomia por escolhas alimentares mais assertivas, críticas e conscientes.

\section{CONSIDERAÇÕES FINAIS}

As ações de educação alimentar e nutricional trouxeram resultados positivos no que se refere à ampliação de conhecimentos, modificação ou pretensão de modificar as práticas alimentares, compreensão de como as escolhas alimentares podem afetar o corpo humano e o meio ambiente. Os discentes acolheram a proposta, foram receptivos, participaram ativamente de cada encontro, o que facilitou a troca e construção de conhecimentos.

Através dos resultados ainda foi possível perceber a relevância de abordar esta temática na adolescência para a promoção da alimentação saudável, indicando o poder transformador que tais práticas podem trazer no fomento da autonomia para escolhas mais assertivas, bem como, ao comprometimento de difundir estes conhecimentos para além dos muros da escola.

As atividades auxiliaram no processo de ensino e aprendizagem da fisiologia humana e ampliou o olhar de como o profissional de controle ambiental ao buscar uma alimentação saudável pode contribuir para um meio ambiente melhor.

Satisfeitos com os resultados, sabemos que este foi apenas um start. Uma vez que a alimentação saudável é um tema transversal que deve ser abordado no currículo integrado de forma permanente e contínua para que alcance seu real potencial transformador e auxiliar no processo de reeducação alimentar.

\section{REFERÊNCIAS}

ANVISA. Gerência-Geral de Alimentos. Processo de revisão da regulamentação de rotulagem nutricional: resultados das atividades já desenvolvidas e planejamento das próximas ações. Brasília: Anvisa, 2019. Disponível em: http://portal.anvisa.gov.br/documents/219201/2782895/Rotulagem+Nutricional .pdf/4d540957-2a21-460a-9275-235deb3cde03. Acesso em: 05 maio 2020.

ÁVILA, R. S. et. al. Educação alimentar e nutricional para adolescentes: O protagonismo como estratégia para práticas alimentares saudáveis. Revista Saúde e Desenvolvimento Humano. Canoas. v. 7, n. 3, p. 39-48, 2019. Disponível em: 
https://revistas.unilasalle.edu.br/index.php/saude desenvolvimento/article/vie w/5053/pdf. Acesso em: 22 abril 2020.

BOOG, M. C. F. Educação em Nutrição: integrando experiências.

Campinas, SP: Komedi, 2013.

BRASIL. Ministério da Saúde. Secretaria de Atenção à Saúde. Departamento de Atenção Básica. Guia alimentar para a população brasileira. 2. ed. Brasília: MS, 2014. Disponível em:

https://bvsms.saude.gov.br/bvs/publicacoes/guia alimentar populacao brasil eira 2ed.pdf. Acesso em: 02 fevereiro 2019.

BRASIL. Ministério da Saúde. Universidade Federal de Minas Gerais.

Instrutivo: metodologia de trabalho em grupos para ações de alimentação e nutrição na atenção básica. Brasília: MS, 2016. Disponível em:

https://bvsms.saude.gov.br/bvs/publicacoes/instrutivo metodologia trabalho alimentacao nutricao atencao basica.pdf. Acesso em: 25 outubro 2019.

BRASIL. Ministério da Saúde. Secretaria de Atenção Básica. Departamento de ações programáticas e estratégicas. Proteger e cuidar da saúde de adolescente na atenção básica. Brasília: MS, 2017. Disponível em: https://bvsms.saude.gov.br/bvs/publicacoes/proteger cuidar adolescentes at encao basica.pdf. Acesso em: 20 maio 2019.

BRASIL. Ministério da Saúde. Secretaria de Vigilância em Saúde. Departamento de Análise em Saúde e Vigilância de Doenças Não Transmissíveis. Vigitel Brasil 2018: vigilância de fatores de risco e proteção para doenças crônicas por inquérito telefônico. Brasília: MS, 2019. Disponível em: https://portalarquivos2.saude.gov.br/images/pdf/2019/julho/25/vigitelbrasil-2018.pdf. Acesso em: 15 junho 2019.

BRASIL. Ministério do Desenvolvimento Social e Combate à Fome. Secretaria Nacional de Segurança Alimentar e Nutricional. Marco de referência a educação alimentar e nutricional para as políticas públicas. Brasília: MDS, 2012. Disponível em: http://www.mds.gov.br/webarquivos/publicacao/seguranca alimentar/marco EAN.pdf. Acesso em: 18 janeiro 2019.

CARNEIRO, C. de S. et. al. Excesso de peso e fatores associados em adolescentes de uma capital. Revista Brasileira de Epidemiologia. v. 20, n.2, abr.-jun., p.260-273, rio de janeiro, 2017. Disponível em: https://www.scielo.br/pdf/rbepid/v20n2/1980-5497-rbepid-20-02-00260.pdf. Acesso em:15 fevereiro 2020.

CARVALHO, M. C. V. S. et. al. Avaliação de ações de Educação Alimentar e Nutricional na escola. Instituto de Nutrição Josué de Castro/ UFRJ para o projeto MDS/SESAN/ CNPq, 2016. Disponível em:

http://www4.planalto.gov.br/consea/publicacoes/avaliacao-de-acoes-de- 
ean/avaliacao-de-acoes-de-ean-na-escola/1-avaliacao-de-acoes-de-ean-naescola.pdf. Acesso em: 11 novembro 2019.

COSTA, M. de C. et. al. Experiência lúdica de promoção de alimentação saudável no ambiente escolar: satisfação e aprendizado dos estudantes. 0 mundo da saúde. São Paulo. v. 40, n. 1, p. 38.50, 2016. Disponível em: http://www.unirio.br/cecane/arquivos/experiencia ludica promocao.pdf. Acesso em: 10 dezembro 2019.

GOMES, M. E. M.; TEIXEIRA, C. Aproveitamento integral dos alimentos: qualidade nutricional e consciência ambiental no ambiente escolar. Ensino, saúde e ambiente. Niterói. v. 10, n. 1, p. 203-217, 2017. Disponível em: https://periodicos.uff.br/ensinosaudeambiente/article/view/21257/12729. Acesso em: 15 abril 2020.

MAGALHÃES, Q. V. B.; CAVALCANTE, J. L. P. Educação alimentar e nutricional como intervenção em hábitos alimentares saudáveis no ambiente escolar. Sanare. Sobral. v. 18, n. 1, p. 59-67, 2019. Disponível em: https://sanare.emnuvens.com.br/sanare/article/view/1306/687. Acesso em: 10 março 2020.

MINAYO, M. C. de S. O desafio do conhecimento: pesquisa qualitativa em saúde. 9ed. São Paulo: Hucitec, 2006.

SILVA, L. S, et. al. Semeando saúde: Educação ambiental e alimentar em escolas de Itaqui/RS. Extensio. Florianópolis. v. 17, n. 35, p. 108-125, 2020.Disponível em:

https://periodicos.ufsc.br/index.php/extensio/article/view/18070221.2020v17n35p108. Acesso em: 20 maio 2020.

SILVEIRA, J. A. C. et al. A efetividade de intervenções de educação nutricional nas escolas para prevenção e redução do ganho excessivo de peso em crianças e adolescentes: uma revisão sistemática. Jornal de Pediatria. Rio de Janeiro. v. 87, n. 5, p. 382-392, 2011. Disponível em: https://www.scielo.br/scielo.php?pid=S0021-

75572011000500004\&script=sci abstract\&tlng=pt. Acesso em: 18 janeiro 2019.

VAZ, E. da G. V.; RIBEIRO, S. R. P.; RUFINO, M. do S. M. Os reflexos profilático e pedagógico da educação alimentar nas escolas do Maciço de Baturiré, Ceará. Revista Brasileira de Extensão Universitária. Chapeco. v. 11, n. 1, p. 01.11, 2020. Disponível em:

https://periodicos.uffs.edu.br/index.php/RBEU/article/view/10928. Acesso em 29 abril 2020.

WHO. Global status report on noncommunicable diseases 2014. Geneva: World Health Organization, 2014. 